\title{
Impact of simulated mechanical hedge pruning and wood age on new shoot demography and return flowering in olive trees
}

\author{
Valeria Albarracín ${ }^{1,3} \cdot$ Antonio J. Hall $^{2} \cdot$ Peter S. Searles ${ }^{1} \cdot$ M. Cecilia Rousseaux ${ }^{1}$ (i)
}

Received: 4 January 2018 / Accepted: 10 August 2018

○) Springer-Verlag GmbH Germany, part of Springer Nature 2018

\begin{abstract}
Key message More vigorous watersprouts and fewer low vigor shoots form as wood age increases at the cutting points with greater canopy pruning depth in olive trees, which reduces return flowering. Such information is relevant to long-term olive orchard pruning strategies in hedgerows.

Abstract Demographic analysis of growth responses to pruning in fruit trees seeks the quantification of the typology of new shoots originating from the remaining branches. Pruning of hedgerows using mechanical discs is becoming increasingly common in orchards, but little information is available as to how such pruning, which does not discriminate between branch size, wood age at the cutting point, branch type, or position, modifies subsequent new shoot demography. Hence, the experiment described in this study in young olive trees (cv. Arbequina) assessed the following questions: (1) Is the type and growth of new shoots associated with the intensity of mechanical pruning and/or the wood age on which they grow? (2) How many growing seasons does it take for new shoots formed after pruning to flower? The principal hypothesis was that a greater proportion of vigorous watersprouts form compared to low vigor shoots as wood age at the cutting points increases with canopy pruning depth, and that the watersprouts have low flowering potential. Both new shoot growth and return flowering were monitored on exposed supporting wood over several growing seasons after implementing three winter $(25 \mathrm{~W}, 50 \mathrm{~W}$, and $75 \mathrm{~W}$ ) pruning levels of increasing intensity and one summer pruning $(75 \mathrm{~S})$ treatment along with an unpruned control $(\mathrm{CON})$. As hypothesized, a greater number and elongation of vigorous watersprouts were found as wood age increased at the cutting points with greater winter pruning intensity, and the watersprouts had low levels of return flowering even 3 full years after pruning compared to the CON. Growth of low vigor shoots was relatively more important than watersprout growth in the severe summer pruning treatment, although 3 years after the summer pruning flowering was not fully recovered. In contrast, the more lightly pruned winter treatments $(25 \mathrm{~W}, 50 \mathrm{~W})$ did not show significant differences in flowering with the $\mathrm{CON}$ at the end of 3 years. Thus, mechanical hedge pruning in olive trees should be light-to-moderate to avoid the formation of watersprouts on older wood, which leads to long-term reductions in flowering.
\end{abstract}

Keywords Lateral branching $\cdot$ Return flowering $\cdot$ Shoots $\cdot$ Vegetative growth $\cdot$ Watersprouts $\cdot$ Wood age

\section{Communicated by Grote.}

M. Cecilia Rousseaux

crousseaux2@gmail.com; crousseaux@conicet.gov.ar

1 Centro Regional de Investigaciones Científicas y Transferencia Tecnológica de La Rioja (CRILAR-Provincia de La Rioja-UNLaR-SEGEMAR-UNCa-CONICET), Entre Ríos y Mendoza s/n, 5301 Anillaco, La Rioja, Argentina

2 IFEVA, Facultad de Agronomía, Universidad de Buenos Aires/CONICET, Av. San Martín 4453, C1417DSE Buenos Aires, Argentina

3 Present Address: Subsecretaria de Agricultura, Ministerio de Agroindustria, Av. Paseo Colón 982, C1063ACW Buenos Aires, Argentina

\section{Introduction}

Branch demography has long been recognized as an important aspect of the growth of woody perennials (Harper and White 1974). After fruit trees are pruned, demographic analysis seeks the quantification and typology of new shoots originating from the remaining branches (Stephan et al. 2007). Pruning of hedgerows using mechanical discs affects new shoot type, because it performs cuts without discriminating between branch size, wood age at the cutting point, branch type, or position. The resulting demography can, in turn, affect future reproductive development, but few assessments of how new shoot type influences flowering after 
pruning have been undertaken in either deciduous fruit tree species like apple (Stephan et al. 2007) and peach (Bevacqua et al. 2012) or in evergreen fruit trees (mango-Normand et al. 2009).

Currently, available information shows that pruning affects shoot demography and subsequent flowering due to changes in shoot growth rate and the positioning of the fruiting buds (i.e., lateral or terminal) (Costes et al. 2003; Lauri et al. 1996; Stephan et al. 2007). In apple, winter pruning stimulated new shoot growth and increased the probability of buds flowering the next growing season, although this response was somewhat influenced by the growth and flowering characteristics of each cultivar (Fumey et al. 2011; Mohammadi et al. 2013; Stephan et al. 2007). In contrast, summer pruning reduced both new shoot growth ( $\mathrm{Li}$ et al. 2003; Li and Lakso 2004) and return flowering due to fewer potential fruiting sites (Fumey et al. 2011). In peach, increasing the severity of winter pruning stimulated the number and length of vigorous watersprouts, but much less response was apparent in less vigorous shoots and flowering was not examined (Bussi et al. 2011).

In olive, demographic analysis of shoots and return flowering was performed on 5-year-old branches of trees with different fruit loads the previous season (Castillo-Llanque and Rapoport 2011). Prior fruit load was found to be the main determinant of inflorescence development with no significant effect of shoot type and length on return flowering. In that study, shoots were classified according to age and whether they were lateral or apical shoots, without a specific classification related to vigor. Because olive trees consist of both low vigor shoots with low, horizontal insertion angles and short internodes as well as vigorous watersprouts that are more vertically oriented with long internodes (Gucci and Cantini 2000), further study is needed to assess how modifications in vigor associated with mechanical pruning affect the number, length, and return flowering of new shoots.

Pruning is a necessary practice to control canopy size and reduce alternate bearing in olive orchards, but the timing and depth of mechanical hedge pruning into the canopy must be considered (Albarracín et al. 2017; Lavee 2007). After winter pruning, more vigorous watersprouts are expected than under non-pruned conditions (Gucci and Cantini 2000), while summer pruning is most often associated with fewer new shoots and less vigor (Albarracín et al. 2017). The depth of mechanical pruning into the canopy would likely not only modify the number and type of new shoots and their distribution, but also the age of the wood that becomes exposed and on which the new shoots originate.

Although practical field experience in many fruit trees suggests that shoot elongation often increases with wood age at the cutting points, a few studies have experimentally evaluated the effect of wood age on shoot demography and reproductive characteristics (Lauri et al. 1996; Tiyayon and Strik 2010; Stanley 2016). Interestingly, experimental evidence in kiwifruit found that neither shoot length nor fruit number differed with wood age after summer pruning (Tiyayon and Strik 2010). In studies with several apple and apricot cultivars, fruit set was lower in shoots on 1-yearold wood than on 2- or 3-year-old wood (Lauri et al. 1996; Stanley 2016), but older wood also tended to show low fruit set in apricot (Stanley 2016). To the best of our knowledge, the effect of wood age on the subsequent shoot demography and reproductive characteristics after winter and summer mechancial pruning of olive trees has not been previously examined.

In olive trees, the lateral buds found on shoots can be either vegetative or reproductive (Sanz-Cortés et al. 2002). In contrast to pome fruit trees such as apple, no specific predominant floral shoots (i.e., short spurs) are present in olive trees. The inflorescence buds are formed on shoot growth from the previous season (Connor and Fereres 2005), and floral induction appears to occur in the early winter under cold temperatures based on recent molecular evidence associated with genes encoding flowering locus $\mathrm{T}$ (Haberman et al. 2017). The reproductive buds then require further low temperatures to release endodormancy and for bloom to occur during the spring after the accumulation of warmer temperatures (De Melo-Abreu et al. 2004; Hackett and Hartmann 1964). In contrast, vegetative buds appear to have an easily reversible endodormancy (Lopez-Bernal et al. 2017). These vegetative buds can result in two main shoot types, short, low vigor shoots, or vigorous watersprouts. Given that vigor positively correlates with gibberellin concentrations in apical meristems (Elliott et al. 2001) and that hormones such as gibberellins appear be involved in flower induction (Haberman et al. 2016, 2017), changes in shoot demography due to pruning intensity or wood age may influence flowering intensity in olive. For defining appropriate orchard management strategies, the number of growing seasons between mechanical pruning and achieving sufficient flowering for obtaining high fruit yields is critical information.

The increase in plant density in olive orchards over the last 20 years has made mechanization a critical component of orchard management (Connor et al. 2014; Tombesi et al. 2014). Nevertheless, experimental studies addressing the pruning of olive hedgerows in well-known cultivars with varying degrees of vigor and branch architecture are very scarce (Vivaldi et al. 2015). Albarracín et al. (2017) analyzed total shoot growth in response to simulated mechanical pruning intensity in cv. Arbequina, the most planted hedgerow cultivar worldwide. However, no further analysis on shoot type or the impact of wood age was included. Furthermore, the possible influence of these demographic changes on the following return flowering has not been considered.

The present study assessed the following questions: (1) Is the type and growth of shoots associated with the intensity 
of mechanical pruning and/or the wood age on which they grow? (2) How many growing seasons does it take for new shoots formed after pruning to flower? The importance of the timing of pruning (i.e., winter versus summer) was also addressed at one level of pruning severity. Our principal hypothesis was that a greater proportion of vigorous watersprouts form compared to low vigor shoots as wood age at the cutting points increases with canopy pruning depth, and that the watersprouts have low flowering potential.

\section{Materials and methods}

\section{Experimental site and pruning treatments}

Extensive description of the experimental site and mechanical pruning treatments are given in Albarracín et al. (2017). Briefly, the experiment was conducted over three growing seasons from August 2009 to September 2012 in a commercial olive orchard (Olea europaea $\mathrm{cv}$. Arbequina) near the city of La Rioja, Argentina (lat. $29^{\circ} 17^{\prime} \mathrm{S}$, long. $66^{\circ} 45^{\prime} \mathrm{W}$ ). The trees were 5 years old when the experiment started, orchard rows had a north-south orientation, and tree spacing was $6 \mathrm{~m}$ within rows and $8 \mathrm{~m}$ between rows ( 208 trees ha ${ }^{-1}$ ). Canopy horizontal diameter averaged $2.2 \mathrm{~m}$ before pruning and the tree height minus the skirt-to-ground distance was $2.7 \mathrm{~m}$.

Pruning was performed on individual trees in an "on" year with fruit load being high (>3400 fruit $\mathrm{m}^{-3}$ ) according to Trentacoste et al. (2010). Three different intensity winter pruning $(\mathrm{W})$ treatments and one early summer pruning (S) treatment were applied along with an unpruned control (CON). Winter pruning was performed in late August 2009 when vegetative and reproductive buds could be easily distinguished, and summer pruning was done in the early December 2009 soon after massive pit hardening. Both the entire east and west sides of the trees were pruned at different distances from the outer canopy surface using manual clippers. Such pruning simulated the mechanical disk pruning technique that is increasingly common in many olive regions. The pruned distances were $0.25(25 \mathrm{~W}), 0.50(50 \mathrm{~W})$, and $0.75 \mathrm{~m}(75 \mathrm{~W})$ from the canopy outer surface for the winter pruning treatments and $0.75 \mathrm{~m}(75 \mathrm{~S})$ for the summer pruning treatment. These pruning intensities represent the wide range of distances used for mechanical hedge pruning in most olive orchards, and included a broad range of canopy volume removal (6-40\%; Albarracín et al. 2017). The average tree diameter in the east-west direction after pruning was $1.70,1.20$, and $0.80 \mathrm{~m}$ for the three pruning distances. The tops of the trees were not pruned in any of the treatments during the study, because tree heights were less than the $3.5 \mathrm{~m}$ maximum allowed for by many over-row harvesters.
The experimental design was a completely randomized block design with six blocks. There were a total of five trees within each block including one tree from each pruning treatment and the control ( 6 blocks $\times 5$ trees $=30$ trees). All trees were drip irrigated to meet $100 \%$ of their crop evapotranspiration requirements for an annual potential evapotranspiration of $1714 \mathrm{~mm}$ in year 1 and $1627 \mathrm{~mm}$ in year 2 using a crop coefficient $\left(K_{\mathrm{c}}\right)$ of 0.7 during the growing season and a $K_{\mathrm{c}}$ of 0.4 during the winter months (Rousseaux et al. 2009). Irrigation levels were further adjusted each year by considering the canopy size of each pruned treatment and the control to calculate reduction coefficients $\left(K_{\mathrm{r}}\right)$ that represented the ground area shaded by the tree canopies (Fereres et al. 1981). Depending on canopy size and effective precipitation, the annual irrigation applied ranged from 167 to $268 \mathrm{~mm}$ in year 1 and from 152 to $277 \mathrm{~mm}$ in year 2 (Table 1). Annual precipitation was $361 \mathrm{~mm}$ in year 1 and $326 \mathrm{~mm}$ in year 2 with an effective precipitation of 0.40 being calculated for precipitation events greater than $5 \mathrm{~mm}$ based on the approximate ground surface area occupied by the root systems of these trees.

\section{Pruned branch and shoot classification by wood age}

Immediately after the winter and summer pruning events in 2009 , the total number of branches or shoots cut and their wood age at the point of cutting were evaluated for the different pruning intensities and the timing of the pruning event. Branch refers to a larger unit of growth than a shoot with branches having multiple ramification points bearing several smaller shoots. Shoots were defined as growth units that formed within a year and positioned on wood formed in the current or previous years. Wood age at the points of cutting was estimated using the protocol recommended by CastilloLlanque and Rapoport (2011) for olive trees. This protocol primarily estimates wood age by quantifying branching order as a function of the number of lateral branching and

Table 1 Annual irrigation applied and the coefficient of reduction $\left(K_{\mathrm{r}}\right)$ during year 1 (September 2009-August 2010) and year 2 (September 2010-August 2011) for each pruning treatment and the unpruned control

\begin{tabular}{llllll}
\hline Treatments & \multicolumn{3}{l}{ Year 1} & & Year 2 \\
\cline { 2 - 3 } \cline { 6 - 6 } & Irrigation $(\mathrm{mm})$ & $K_{\mathrm{r}}$ & & Irrigation $(\mathrm{mm})$ & $K_{\mathrm{r}}$ \\
\hline CON & 268 & 0.30 & & 277 & 0.40 \\
$25 \mathrm{~W}$ & 234 & 0.27 & & 242 & 0.37 \\
$50 \mathrm{~W}$ & 201 & 0.22 & & 208 & 0.31 \\
$75 \mathrm{~W}$ & 167 & 0.19 & & 228 & 0.33 \\
$75 \mathrm{~S}$ & 211 & $0.30 / 0.19$ & & 192 & 0.29 \\
\hline
\end{tabular}

Total water applied was irrigation plus effective precipitation. The summer pruning treatment had two $K_{\mathrm{r}}$ values in year 1 (one before and one after pruning) 
apical extension events. Other criteria are secondarily used to improve the estimates including the presence of leaves, lateral buds, and the external appearance of the bark. The lifespan of leaves and lateral buds is usually considered to be a maximum of 3 and 2 years, respectively. To independently assess wood age at the points of cutting, branch and shoot diameter as well as the number of growth rings were measured at the points of cutting. Average diameter values were $5.1 \mathrm{~mm}$ for 1-year-old shoots and $21.4 \mathrm{~mm}$ for 4-year-old branches. The wood age estimates obtained from the protocol of Castillo-Llanque and Rapoport (2011) and those of the branch and shoot diameter methodology were most often in good agreement, and the wood ages at the cutting points reported in this study are the ages estimated from the protocol of Castillo-Llanque and Rapoport (2011). Wood age was considered to be an appropriate variable for classifying the pruned material, because an estimate of the timeframe under which the previous growth occurred is relevant for orchard management.

\section{New shoot growth and demography}

On each pruned tree, 12 base branches (BB; 6 on the east and 6 on the west face of the tree) were marked at heights of between 1 and $2 \mathrm{~m}$ on which new vegetative growth was evaluated. The term 'base branch' refers to the underlying woody support structure just below the cutting point. Shoot growth, both shoot number and elongation, on the marked BB was recorded at the end of each of the two growing seasons (year 1, 2009-2010 and year 2, 2010-2011). The evaluated new growth was restricted to shoots growing within $10 \mathrm{~cm}$ of the cutting point on the BB. There were only a few cases $(<5 \%)$ in which shoots formed prior to pruning were present in this $10 \mathrm{~cm}$ zone, and the growth of these shoots was not considered in the analysis. The wood ages of the marked BB ranged from 0 to 4 years depending on the pruning intensity applied. In the control trees, 12 well-illuminated shoots were selected in the outer portion of the canopy whose diameters at their base were similar to those of the $25 \mathrm{~W}$ base branches. These selected shoots were between 0 and 1 years of age, which is representative of the wood age at this outer canopy position. Age 0 corresponded to shoots that grew from buds generated the previous season.

The new growth was classified into four principal types: low vigor shoots, lateral shoots (lat-shoots) branching from low vigor shoots, high vigor watersprouts, and lateral-watersprouts (lat-watersprouts) branching from watersprouts (Fig. 1). Although it is certain that there was a continuous gradient in growth rate, several criteria including angle of insertion, internode length, number of leaves per internode, and leaf shape were used to classify growth according to vigor (see Gucci and Cantini 2000). New growth with low horizontal insertion angles, short internodes $(<3.0 \mathrm{~cm})$, and two elongated leaves per node was classified as low vigor shoots and lat-shoots. In contrast, watersprouts and lat-watersprouts had vigorous growth with
Fig. 1 Photograph showing the appearance of a moderately pruned tree $(50 \mathrm{~W})$ in late winter shortly after simulated mechanical hedge pruning (a), diagram of the shoot types originating from base branches (BB) after pruning (b), and a photograph of a marked base branch 3 months after pruning with new shoot growth (c). $B B$ underlying woody support structure just below the cutting point (CP), $S$ new low vigor shoot growing from the $\mathrm{BB}$, $L S$ new low vigor lateral shoot growing from $\mathrm{S}, L L S$ secondorder LS, $W$ new watersprout, $L W$ lateral shoot on a watersprout, $L L W$ second-order lateral watersprout
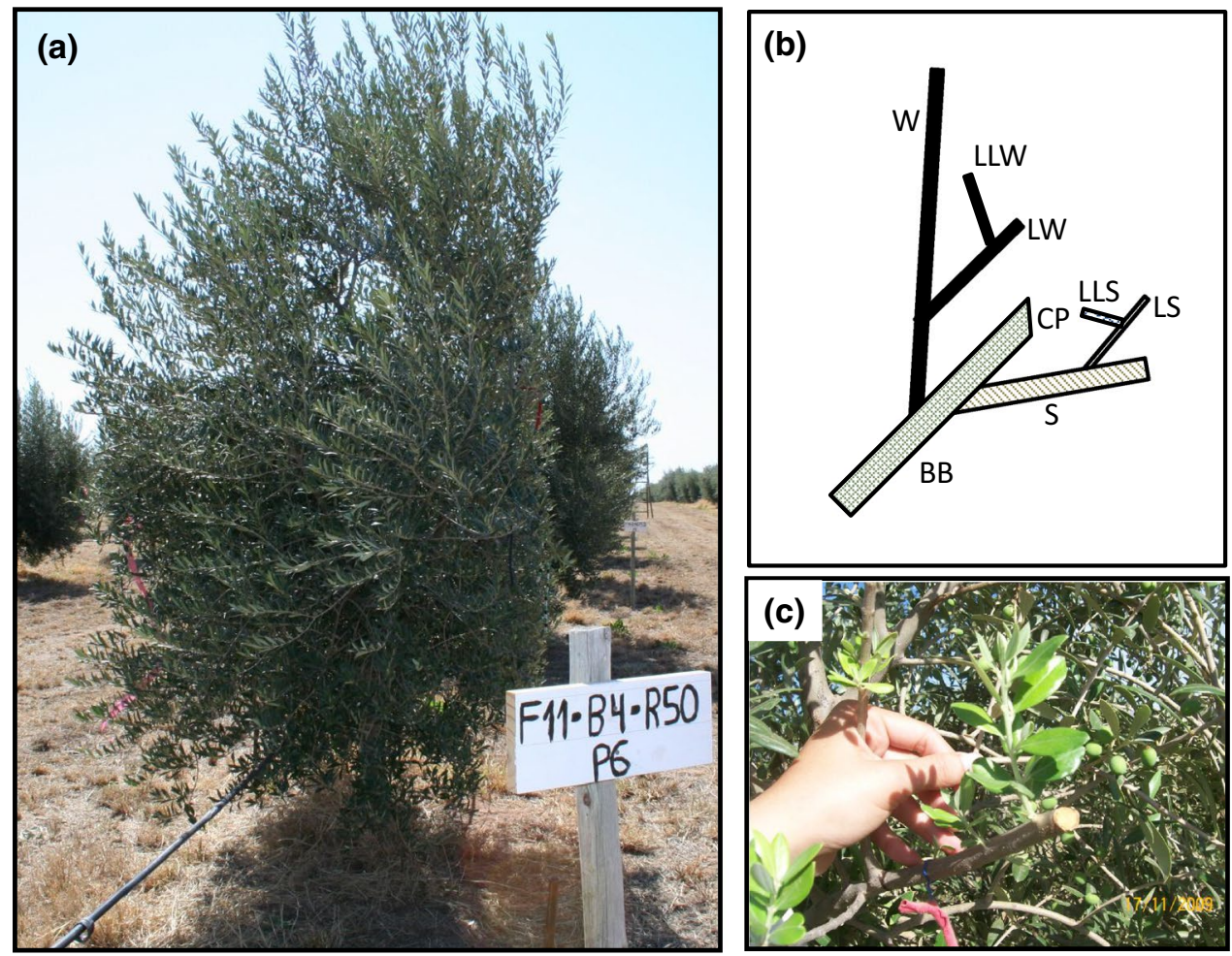
high vertical insertion angles, long internodes $(>3.0 \mathrm{~cm})$, and 3-4 rounded leaves per node in some cases. In year 2, a very small percentage $(0.3 \%)$ of the lat-shoots and lat-watersprouts produced new shoots (i.e., lateral shoots developing on lateral shoots). Due to their low frequency, these shoots were included in the lat-shoot or lat-watersprout categories. We calculated the \% BB that produced shoots, lat-shoots, watersprouts, and lat-watersprouts, a variable indicative of the tendency of BBs to generate new growth in response to pruning. The number of new shoots per BB and the mean elongation of the four growth types were also determined for each pruning treatment. For these variables, year 2 growth values represent the new growth occurring in that year and not the cumulative growth over the 2 years. To achieve this, shoots were measured at the end of each season and year 1 values were subtracted from those of Year 2.

\section{Return flowering}

Flowering on new shoots after pruning was quantified as the percentage of $\mathrm{BB}$ with at least one inflorescence for a given shoot type. The measurements were performed during full bloom from October 1-20 in the spring of 2010, 2011, and 2012. The first measurements coincided with the spring of the second growing season.

\section{Data analysis}

The total number of branches or shoots cut and their wood age at the point of cutting were analyzed using ANOVA to assess potential differences between the pruning treatments. Significant differences $(P<0.05)$ between means were determined using the LSD post-test. This analysis and all others were performed using InfoStat software version 2014 (InfoStat Group, FCA, Universidad Nacional de Córdoba, Argentina) (Di Rienzo et al. 2014).

The responses of new shoot growth and demography to pruning for the \% $\mathrm{BB}$ with shoots, number of shoots per $\mathrm{BB}$, and the elongation of shoots for each category were analyzed using general and mixed linear models for repeated measurements over time, because the observations were made on the same BBs in both years. Because pruning $\times$ year interactions were often significant $(P<0.05)$, differences between pruning treatments within a given year were determined. Data calculated as percentages were transformed prior to analysis using the square root of the arc-sine function.

Preliminary ANOVA analysis showed that pruning intensity did not affect the response of the shoot growth variables to wood age. Thus, the effect of BB wood age on shoot growth is presented for each year with significant differences $(P<0.05)$ between means being determined using the non-parametric Kruskal-Wallis test to account for the BB wood ages being unbalanced between trees. The total number of BB observed was 360 (12 BB per tree $\times 30$ trees), and the sample size $(n)$ was $68,59,128,84$, and 21 for BBs of $0,1,2,3$, and 4 years old, respectively. For return flowering, the non-parametric Kruskal-Wallis test was used for each shoot category due to the high frequency of zeros in the data sets.

\section{Results}

\section{Pruned branch and shoot classification by wood age}

As might be expected, the different pruning intensities modified the number of branches or shoots cut and the wood age at the point of cutting (Table 2). In the winter pruning, the total number of branches or shoots removed increased significantly $(P<0.05)$ with pruning intensity. By contrast, there was no statistically significant difference in the total number of branches or shoots cut between the $75 \mathrm{~W}$ and $75 \mathrm{~S}$ treatments. In all pruning treatments, wood classified as being 1 and 2 years old at the cutting point was much more common (76-98\%) than 3- or 4-year-old wood (Table 2).
Table 2 Total number of branches or shoots cut and their wood age at the point of cutting in the winter $(25 \mathrm{~W}, 50 \mathrm{~W}$, and $75 \mathrm{~W})$ and summer $(75 \mathrm{~S})$ pruning treatments

\begin{tabular}{lllllll}
\hline Treatments & \multicolumn{5}{l}{ Pruned branches or shoots (\#) at the point of cutting } \\
\cline { 2 - 7 } & Total & Age 0 & Age 1 & Age 2 & Age 3 & Age 4 \\
\hline $25 \mathrm{~W}$ & $162 \pm 33 \mathrm{C}$ & $0.5 \pm 0.3 \mathrm{~B} c$ & $100 \pm 12 \mathrm{C} a$ & $59 \pm 20 \mathrm{C} b$ & $4 \pm 2 \mathrm{C} c$ & $0 \mathrm{~B} c$ \\
$50 \mathrm{~W}$ & $274 \pm 17 \mathrm{~B}$ & $0 \mathrm{~B} b$ & $107 \pm 24 \mathrm{C} a$ & $119 \pm 24 \mathrm{BC} a$ & $32 \pm 25 \mathrm{~A} b$ & $0 \mathrm{~B} b$ \\
$75 \mathrm{~W}$ & $395 \pm 25 \mathrm{~A}$ & $0 \mathrm{~B} b$ & $188 \pm 22 \mathrm{~A} a$ & $194 \pm 19 \mathrm{~A} a$ & $11 \pm 2 \mathrm{~B} b$ & $2 \pm 1 \mathrm{AB} b$ \\
$75 \mathrm{~S}$ & $353 \pm 51 \mathrm{AB}$ & $46 \pm 16 \mathrm{~A} b$ & $125 \pm 21 \mathrm{~B} a$ & $144 \pm 14 \mathrm{~B} a$ & $31 \pm 6 \mathrm{~A} b c$ & $6 \pm 1 \mathrm{~A} c$ \\
\hline
\end{tabular}

The values are averages of six trees \pm one standard error. Different upper case letters within each column indicate significant differences $(P<0.05)$ between pruning treatments for the total number of branches or shoots cut and for each wood age. Different lower case letters in italics within each row indicate significant differences between wood ages within each pruning treatment 


\section{Pruning effects on new shoot growth and demography}

The percentage of BBs with low vigor shoots was fairly high in Year 1, decreasing with winter pruning from $78 \%$ in the $25 \mathrm{~W}$ treatment to about $55 \%$ in the more severe $50 \mathrm{~W}$ and $75 \mathrm{~W}$ treatments (Fig. 2a). In contrast, the percentage of BB with high vigor watersprouts was much lower, but it increased with winter pruning intensity from $11 \%$ in $25 \mathrm{~W}$ to $36 \%$ in the $75 \mathrm{~W}$ treatment. Both the percentages of BBs with lat-shoots and lat-watersprouts also increased with winter pruning intensity in year 1 . The summer pruned (75S) trees tended to have more low vigor shoots but less watersprouts, lat-shoots, and lat-watersprouts than the most intensive winter pruned treatment $(75 \mathrm{~W})$. In year 2, the percentage of BBs with new low vigor shoots formed during the second year remained high, decreasing with winter pruning intensity in ylear 2 from $81 \%$ in $25 \mathrm{~W}$ to about $65 \%$ in the $50 \mathrm{~W}$ and $75 \mathrm{~W}$ treatments (Fig. 2b). While statistically significant increases in new watersprouts and lat-watersprouts were still observed in year 2 due to the winter pruning treatments, the percentage of BB with watersprouts (2-13\%) and lat-watersprouts $(0-10 \%)$ was low. In contrast, the percentage of BBs with new lat-shoots greatly increased from year 1 to year 2, but no effect of winter pruning on new lat-shoots was observed in year 2 .

In year 1, the responses of the number of low vigor shoots, watersprouts, lat-shoots, and lat-watersprouts per BB to winter pruning intensity (Fig. 2c) showed patterns similar to those found for the percentage of BBs for these same shoot types. In year 2, there was a large increase in the number of new lat-shoots formed during this growing season in all the treatments, but the response was greatest in the $50 \mathrm{~W}$ and $75 \mathrm{~W}$ pruning treatments (Fig. 2d). This contrasts with no difference being found in the percentage of BB with new lat-shoots in year 2 (Fig. 2b).

Except for lat-shoots, the elongation of all shoot types increased with winter pruning intensity in year 1 (Fig. 2e). The response was greatest in watersprouts of the $50 \mathrm{~W}$ and $75 \mathrm{~W}$ treatments with mean elongations of about $40-50 \mathrm{~cm}$. Watersprout elongation in the summer pruning treatment (75S) was similar to the non-pruned control and the $25 \mathrm{~W}$ pruning treatment with elongations of only about $20 \mathrm{~cm}$. In year 2, there was significantly greater mean elongation for all categories (especially watersprouts), and the pruning treatment response patterns were similar in year 2 to those of year 1 (Fig. 2f).
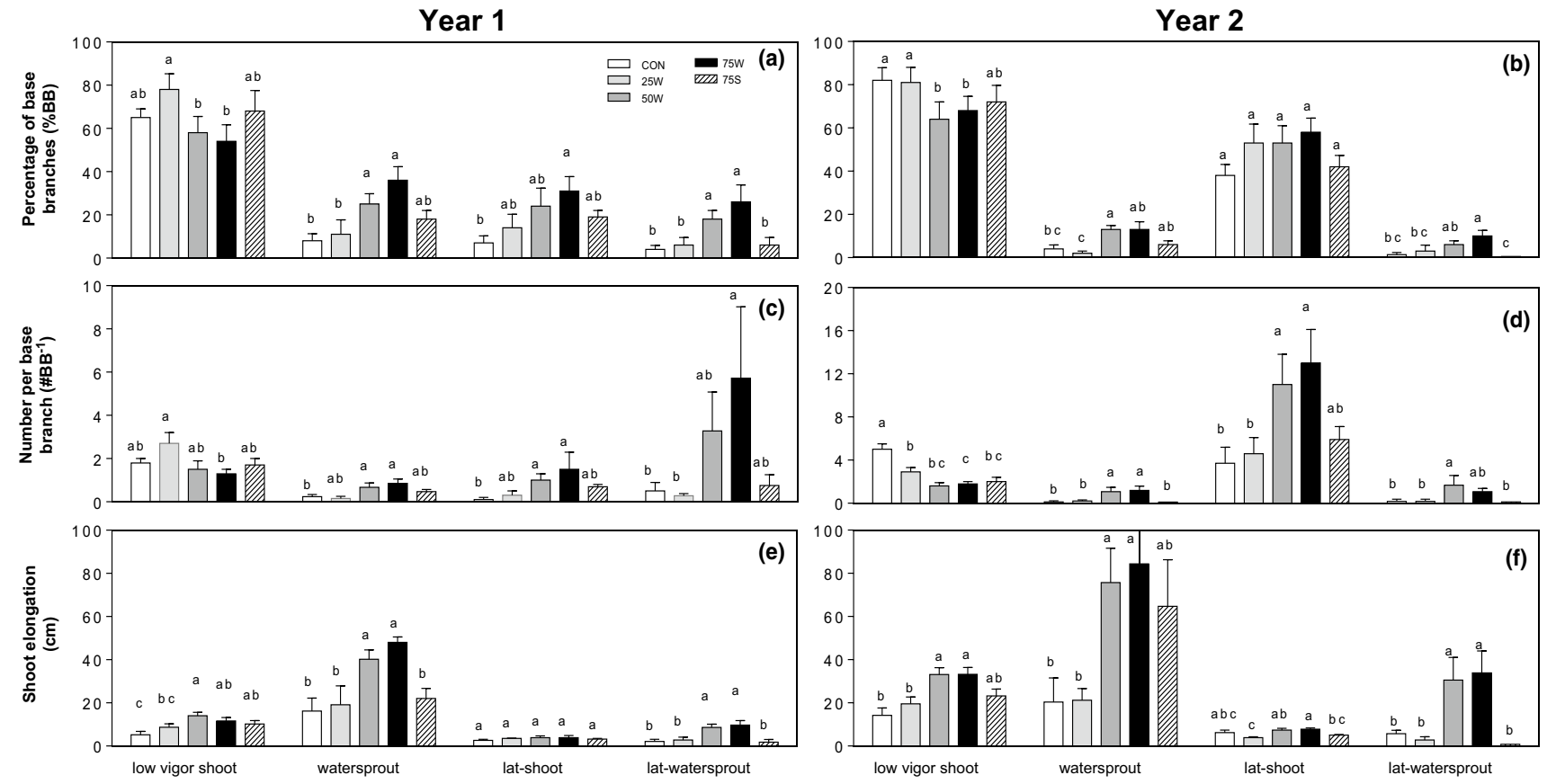

Type of shoot

Fig. 2 Percentage of base branches (\%BB) with new shoots (a, b), number of new shoots per BB (c, d), and shoot elongation $(\mathbf{e}, \mathbf{f})$ for each shoot type and pruning treatment in a given growing season (i.e., year 1 and year 2). New growth was classified in four groups: low vigor shoots, watersprouts, lateral shoots branching from low vigor shoots, and lateral-watersprouts branching from new watersprouts.
In addition to the non-pruned control $(\mathrm{CON})$, there were three winter pruning treatments $(25 \mathrm{~W}, 50 \mathrm{~W}$, and $75 \mathrm{~W})$ and a summer pruning treatment $(75 \mathrm{~S})$. Each bar represents the mean \pm standard error $(n=6$ trees) with each tree having $12 \mathrm{BB}$. Different lower case letters above each bar indicate significant $(P<0.05)$ differences between treatments within shoot type 


\section{Wood age effects on shoot growth and demography}

Wood age had a greater influence on vigorous watersprouts than on less vigorous shoots (Fig. 3). In year 1, the percentage of BB with low vigor shoots after pruning was high for all wood ages with no statistically significant response to wood age (Fig. 3a). In contrast, the percentage of BB with watersprouts was much lower, but it increased strongly with BB wood age (from 6 to 52\%). Despite there being no significant response of low vigor shoots to BB wood age, the percentages of $\mathrm{BBs}$ with lat-shoots was quite pronounced with an increase of 6-48\% with wood age. Lat-watersprouts also increased with BB wood age. Similar to year 1, the percentage of BBs with new low vigor shoots was not affected by BB wood age in year 2, but lat-shoots formed during year 2 continued to increase with wood age (Fig. 3b). While the percentage of $\mathrm{BBs}$ with new watersprouts and lat-watersprouts increased with BB wood age in year 2, this effect was less apparent than in year 1.

In year 1, the responses of the number of low vigor shoots, watersprouts, lat-shoots, and lat-watersprouts per BB to wood age (Fig. 3c) showed patterns similar to those found for the percentage of BBs with new growth for these same shoot types. In contrast, the number of low vigor shoots per BB in year 2 was less from BBs with a wood age of 1,2 , or 3 years old than from 0 to 4 years old (Fig. 3d), while no difference between wood ages for the percentage of BB with new low vigor shoots was found in this same year (Fig. 3b). The response of lat-shoots to wood age is particularly evident in year 2 with the number of new lat-shoots formed during this growing season being five times higher (ten versus two lat-shoots) when BB wood age was 4 years old compared with wood ages of 0 and 1 (Fig. 3d).

Elongation of shoots was lower when BB wood age was 0 compared to ages $1-4(10$ and $18 \mathrm{~cm})$ in Year 1, while watersprout elongation increased exponentially with age up to $58 \mathrm{~cm}$ when grown on 4-year-old wood (Fig. 3e). For all ages, lat-shoots never exceeded $5 \mathrm{~cm}$ and their elongation was not affected by BB wood age, while lat-watersprouts showed a pattern similar to watersprouts with BB wood age. In year 2, the elongation of low vigor shoots, watersprouts, and lat-shoots increased with respect to year 1 for the same shoot type. However, the elongation of lat-watersprouts decreased, particularly on 4-year-old wood (67-35 cm, for years 1 and 2, respectively). For all shoot types, elongation increased with wood age in year 2 (Fig. 3f).
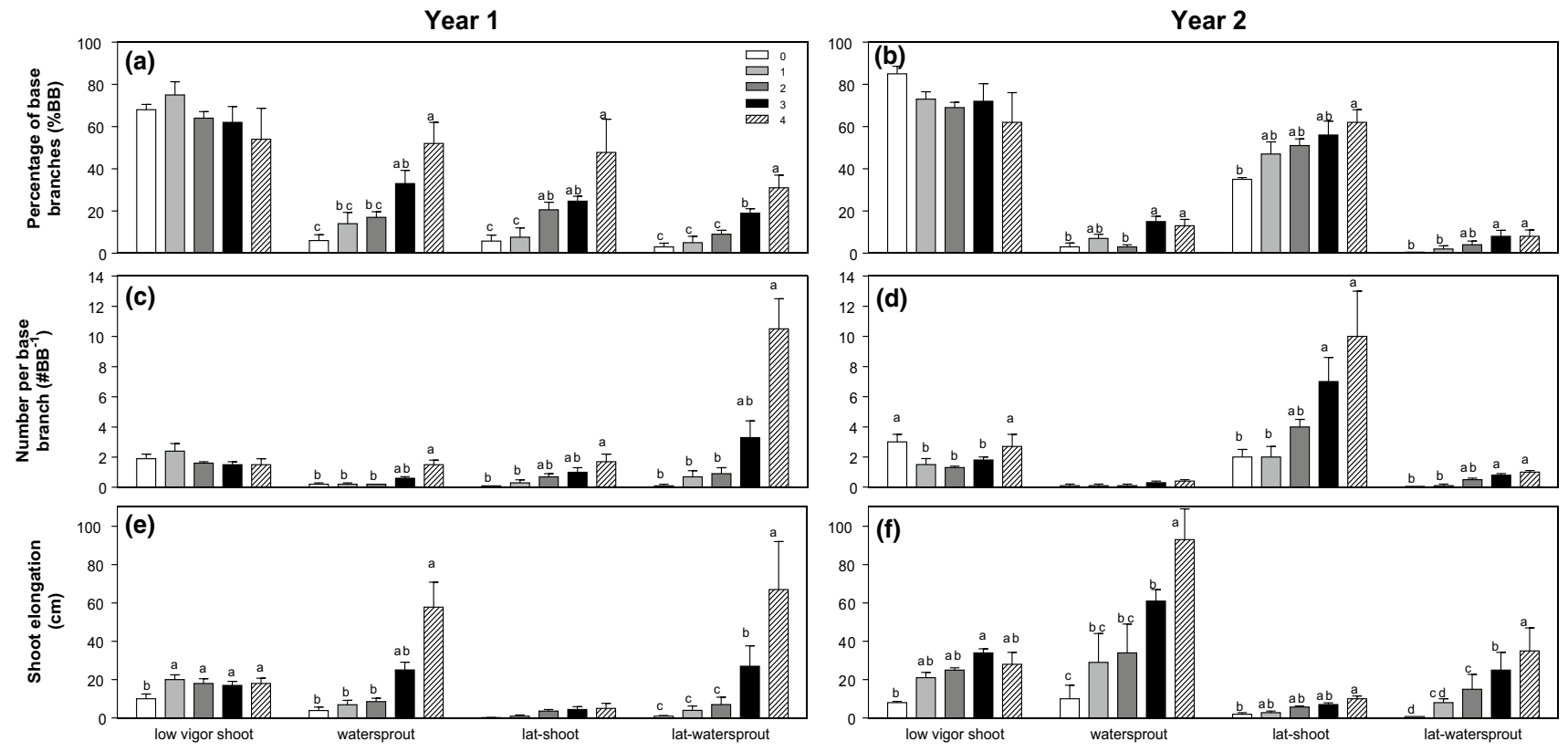

Type of shoot

Fig. 3 Percentage of base branches (\%BB) with new shoots (a, b), number of new shoots per BB (c, d), and shoot elongation $(\mathbf{e}, \mathbf{f})$ for each shoot type and BB wood age in a given growing season (i.e., year 1 and year 2). New growth was classified in four groups: low vigor shoots, watersprouts, lateral shoots branching from low vigor shoots, and lateral-watersprouts branching from new watersprouts.
Wood ages at the point of cutting were 0 (i.e., current season), 1, 2, 3 , and 4 years old. Each bar represents the mean \pm standard error for each BB wood age and shoot type. Different lower case letters above each bar indicate significant $(P<0.05)$ differences between wood ages within shoot type 


\section{Return flowering}

In the years following pruning, the $\%$ of BBs that produced shoots with flowers increased for all shoot types (Fig. 4). Low vigor shoots originating from BBs started to flower 1 year after pruning (spring of 2010; Fig. 4a), and their flowering increased with time, such that flowering in the $25 \mathrm{~W}$ and $50 \mathrm{~W}$ pruning treatments was similar to that of the unpruned control 3 years after pruning (spring of 2012; Fig. 4c). Flowering lat-shoots were not prominent until 1 year later than in low vigor shoots (spring of 2011; Fig. 4b). In addition, the severe summer pruning (75S) did not exhibit a percentage of BBs with flowering low vigor shoots and lat-shoots similar to that of the severe winter pruning $(75 \mathrm{~W})$ until 3 years after pruning (spring of 2012; Fig. 4c). Flowering watersprouts and lat-watersprouts were apparent at very low levels 3 years after pruning in the moderate $(50 \mathrm{~W})$ and severe $(75 \mathrm{~W})$ winter pruning treatments as well as the summer (75S) treatment, but not in the lightly $(25 \mathrm{~W})$ pruned winter treatment.

\section{Discussion}

The demographic analysis in this study of shoot growth and subsequent return flowering following simulated winter and summer mechanical hedge pruning allowed for an evaluation of the intensity and timing of pruning along with wood age at the points of cutting. This assessment complements an earlier study in which total shoot growth (i.e., regardless of shoot types) and crop yield components were determined (Albarracín et al. 2017). In that study, total shoot growth was much greater in the moderate $(50 \mathrm{~W})$ and severe $(75 \mathrm{~W})$ winter pruning treatments compared to the unpruned control, while delaying severe pruning (75S) to the beginning of summer reduced total shoot growth relative to the $50 \mathrm{~W}$ and $75 \mathrm{~W}$ treatments. In the current study, our principal hypothesis was that a greater proportion of vigorous watersprouts form compared to low vigor shoots as wood age at the cutting points increases with canopy pruning depth, and that the watersprouts have low flowering potential. This hypothesis turned out to be largely consistent with the observed results commented upon in the following paragraphs.

When examining growth by shoot type, the \% of BB with vigorous watersprouts and lat-watersprouts as well as their number and elongation generally increased in the $50 \mathrm{~W}$ and
Fig. 4 Percentage of base branches with flowering low vigor shoots, watersprouts, latshoots, and lat-watersprouts in the spring of 2010 (i.e., 1 year after pruning) (a), 2011 (b), and 2012 (c). Flowering on new shoot growth after pruning was quantified as the percentage of $\mathrm{BB}$ with at least one inflorescence for a given shoot type. Pruning treatment codes are shown in Fig. 4a. Each bar represents the mean \pm standard error ( $n=6$ trees) with each tree having 12 BB. Different lower case letters above each bar indicate significant $(P<0.05)$ differences between treatments within each branch type

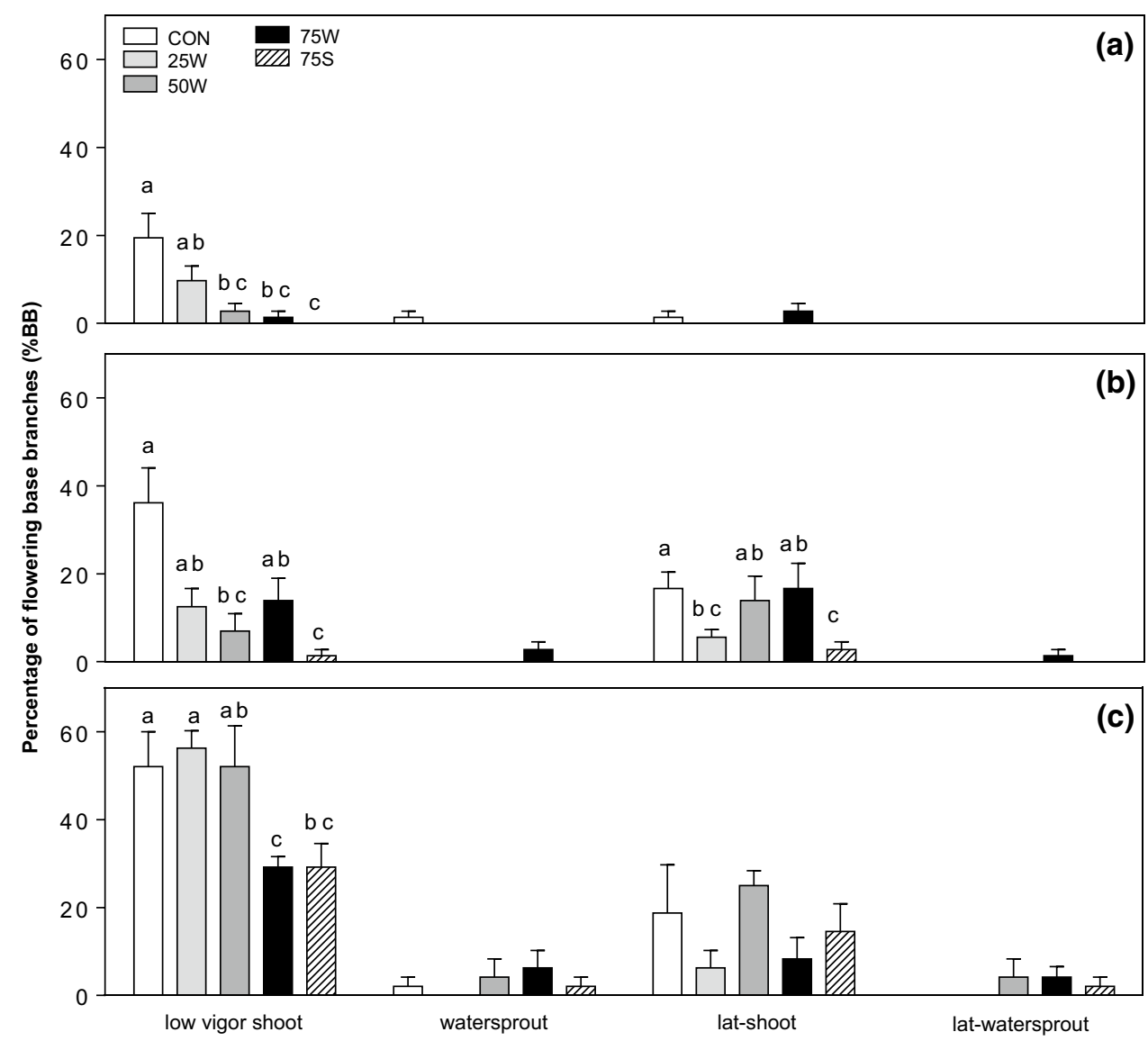


$75 \mathrm{~W}$ winter pruning treatments compared to the unpruned control, the lightly pruned $25 \mathrm{~W}$ treatment, and the summer pruning treatment $(75 \mathrm{~S})$ during the two growing seasons following pruning (Fig. 2). Increases in watersprout number or their length were also observed with manual winter pruning in mango (Vázquez-Valdivia et al. 2009) and peach (Bevacqua et al. 2012; Bussi et al. 2011, 2014; Dalkiliç et al. 2014). In contrast to the watersprouts, the $\%$ of BB with low vigor shoots in our study and their number decreased in the $50 \mathrm{~W}$ and $75 \mathrm{~W}$ treatments, while the average elongation of low vigor shoots increased in these same winter pruning treatments (Fig. 2). Bussi et al. (2011) found, in peach, that both the number and length of fairly non-vigorous shoots decreased with manual pruning intensity.

In contrast to the finding that wood age did not affect shoot length, diameter, internode length, and fruit number per shoot in kiwifruit (Tiyayon and Strik 2010), wood age at the point of cutting in olive trees strongly influenced shoot type and its vigor in subsequent growing seasons (Fig. 3). Vigorous watersprouts and their laterals increased their number and elongation with increasing BB wood age after simulated mechanical pruning (Fig. 3). By contrast, the number of low vigor shoots remained similar or decreased slightly with wood age. Interestingly, the responses to wood age per $\mathrm{BB}$ at the cutting point were independent of the pruning intensity applied. In other words, shoot number and elongation showed no differences in response for the same BB wood age at different canopy pruning depths. The high number of vigorous shoots originating from older wood fortifies the observation that olive trees have a considerable number of adventitious buds under the bark not apparent to the naked eye (Gucci and Cantini 2000). These adventitious buds, also called accessory buds, can remain inactive for several years until a disturbance such as a moderateto-severe pruning event occurs (Fiorino and Marone 2010).

Although the same wood age of the BB gives rise to similar shoot formation and elongation per BB at different canopy depths, greater canopy pruning depth greatly increased the frequency of older branches that were exposed after cutting (Table 2), generating a high number of watersprouts and lat-watersprouts per tree. Thus, from an orchard management standpoint, these results emphasize that wood age should be considered when determining the canopy depth to be mechanically pruned. Future research will need to assess the effects of repeated use of mechanical pruning in maintaining hedgerow size to determine if the wood at the cutting points becomes increasingly older and what effects this would have on future crop productivity.

As expected, return flowering in the growing seasons following pruning was affected by shoot type with shoots of lesser vigor having a greater tendency to bloom than vigorous watersprouts (Fig. 4), and this response occurred regardless of the canopy pruning depth or wood age. The vigorous watersprouts likely had very low levels of return flowering, because high concentrations of gibberellins, which are thought to occur in apical tissues with active growth, are potential inhibitors of floral induction (Bangerth 2009; Elliott et al. 2001; Haberman et al. 2017). In a previous study examining crop load and shoot type effects on return flowering, it was found that shoot type did not greatly affect the return flowering (Castillo-Llanque and Rapoport 2011), but watersprouts were not prevalent in that study.

The above discussion is consistent with the hypothesis that shoot demography and return flowering after simulated mechanical pruning in olive trees are determined by wood age and not pruning canopy depth per se. To the best of our knowledge, such wood age effects have not been evaluated experimentally in olive trees.

A second aspect of our study was an analysis of the timing of pruning on shoot demography and return flowering. For the same pruning intensity, summer pruning resulted in a greater proportion of low vigor shoots compared to watersprouts than with winter pruning (Fig. 2). It is likely that a shift towards less vigorous shoot types occurred with summer pruning due to the well-known reduction in vigorous vegetative growth during fruit growth and olive oil accumulation in the summer months (Dag et al. 2010; Fernández et al. 2015). The timing of pruning had less affect than shoot type on return flowering, and the percentage of flowering base branches was similar on trees pruned in the winter or in the summer for the 3 years after simulated mechanical pruning (Fig. 4).

\section{Conclusions}

This study reports the responses of shoot demography and return flowering in olive trees to the timing and intensity of simulated mechanical hedge pruning, as well as to wood age at the cutting points. The results indicate that more vigorous watersprouts and fewer low vigor shoots form as wood age increases at the cutting points with greater canopy pruning depth. Because return flowering is low in watersprouts, more severe pruning intensities are associated with low levels of return flowering. However, it is also apparent that return flowering recovers in lightly and moderately pruned trees after about 3 years. Given that this study was conducted in a fairly low-density orchard on individual trees, further studies are needed in olive orchards with higher plant densities where light conditions are different and to assess whether pruning should be alternated between sides of the hedgerow to a better crop productivity. In addition, the long-term effect of repeated mechanical pruning at different intensities needs to be determined, because the effect of wood age that increases with each pruning event would likely modify the response to any given pruning intensity. 
Author contribution statement VA performed most of the data collection, data processing, and statistical analyses. VA, $\mathrm{AJH}$, and MCR designed the measurements and sampling protocols. All authors contributed to the overall intellectual development of the study and the writing of the manuscript.

Acknowledgements We thank Emilio Caimi of Olivos Argentinos S.A. for access to their commercial orchard. Eduardo Barbero and Andrés Herrera provided technical support in the field. This research was supported by grants from the Ministerio de Ciencia, Técnica e Innovación Productiva de Argentina (ANPCyT, PICT2012 0178) and CONICET (PIP2012 11220110100545). VA held a doctoral scholarship from CONICET. MCR, AJH, and PSS are members of CONICET.

\section{Compliance with ethical standards}

Conflict of interest The authors declare that they have no conflict of interest.

\section{References}

Albarracín V, Hall AJ, Searles PS, Rousseaux MC (2017) Responses of vegetative growth and fruit yield to winter and summer mechanical pruning in olive trees. Sci Hortic 225:185-194

Bangerth KF (2009) Floral induction in mature, perennial angiosperm fruit trees: similarities and discrepancies with annual/biennial plants and the involvement of plant hormones. Sci Hortic 122:153-163

Bevacqua D, Genard M, Lescourret F (2012) A simple model to predict the probability of a peach (Prunus persicae) tree bud to develop as a long or short shoot as a consequence of winter pruning intensity and previous year growth. PloS One 7:1-6

Bussi C, Bruchou C, Lescourret F (2011) Response of watersprout growth to fruit load and intensity of dormant pruning in peach tree. Sci Hortic 130:725-731

Bussi C, Genard M, Horticoles S, Avignon F (2014) Thinning and pruning to overcome alternate bearing in peach trees. Eur J Hortic Sci 79:313-317

Castillo-Llanque FJ, Rapoport HF (2011) Relationship between reproductive behavior and new shoot development in 5-year-old branches of olive trees (Olea europaea L.). Trees 25:823-832

Connor DJ, Fereres E (2005) The physiology of adaptation and yield expression in olive. Hortic Rev 31:155-229

Connor DJ, Gómez-del-Campo M, Rousseaux MC, Searles PS (2014) Structure, management and productivity of hedgerow olive orchards: a review. Sci Hortic 169:71-93

Costes E, Sinoquet H, Kelne JJ, Godin C (2003) Exploring within-tree architectural development of two apple tree culitivars over 6 years. Ann Bot 99:91-104

Dag A, Bustan A, Avni A, Tzipori I, Lavee S, Riov J (2010) Timing of fruit removal affects concurrent vegetative growth and subsequent return bloom and yield in olive (Olea europaea L.). Sci Hortic 123:469-472

Dalkiliç GG, Dalkiliç Z, Mestav HO (2014) Effect of different pruning severity on vegetative growth in peach (Prunus persica). Türk Tarım ve Doğa. Bilimleri 7:1505-1508

De Melo-Abreu JP, Barranco D, Cordeiro AM, Tous J, Rogado BM, Villalobos FJ (2004) Modelling olive flowering date using chilling for dormancy release and thermal time. Agric For Meteorol 125:117-127
Di Rienzo JA, Casanoves F, Balzarini MG, Gonzalez L, Tablada M, Robledo CW (2014) InfoStat versión 2014. Grupo InfoStat. FCA, Universidad Nacional de Córdoba, Argentina. http://www. infostat.com.ar. Accessed 15 Dec 2017

Elliott RC, Ross JJ, Smith JJ, Lester DR, Reid JB (2001) Feedforward regulation of gibberellin deactivation in pea. J Plant Growth Regul 20:87-94

Fereres E, Pruitt WO, Beutel JA, Henderson DW, Holzapfel E, Shulbach H, Uriu K (1981) ET and drip irrigation scheduling. In: Fereres E (ed) Drip irrigation management. University of California Division of Agriculture Science, Tulelake, pp. 8-13

Fernández FJ, Ladux JL, Searles PS (2015) Dynamics of shoot and fruit growth following fruit thinning in olive trees: same season and subsequent season responses. Sci Hortic 192:320-330

Fiorino P, Marone E (2010) The fate of lateral buds in the olive (Olea europaea L. ssp. europaea var. europaea). A first report. Adv Hortic Sci 24:29-34

Fumey D, Lauri P, Guédon Y, Godin C, Costes E (2011) How young trees cope with removal of whole or parts of shoots: an analysis of local and distant responses to pruning in 1-year-old apple (Malus $\times$ domestica; Rosaceae) trees. Am J Bot 98:1737-1751

Gucci R, Cantini C (2000) Pruning and training systems for modern olive growing. CSIRO, Collingwood

Haberman A, Ackerman M, Crane O, Kelner JJ, Costes E, Samach A (2016) Different flowering response to various fruit loads in apple cultivars correlates with degree of transcript reaccumulation of a TFL1-encoding gene. Plant J 87:161-173

Haberman A, Bakhshian O, Cerezo-Medina S, Paltiel J, Adler C, Ben-Ari G, Mercado J (2017) A possible role for flowering locus T-encoding genes in interpreting environmental and internal cues affecting olive (Olea europaea L.) flower induction. Plant Cell Environ 7:1-18

Hackett WP, Hartmann HT (1964) Inflorescence formation in olive as influenced by low temperature, photoperiod, and leaf area. Bot Gaz 125:65-72

Harper JL, White J (1974) The demography of plants. Ann Rev Ecol Syst 5:419-463

Lauri PE, Terouanne E, Lespinasse JM (1996) Quantitative analysis of relationships between inflorescence size, bearing-axis size and fruit-set-an apple tree case study. Ann Bot 77:277-286

Lavee S (2007) Biennial bearing in olive (Olea europaea L.). Annales Ser His Nat 17:101-112

Li KT, Lakso AN (2004) Photosynthetic characteristics of apple spur leaves after summer pruning to improve exposure to light. HortSci 39:969-972

Li KT, Lakso AN, Piccioni R, Robinson T (2003) Summer pruning reduces whole-canopy carbon fixation and transpiration in apple trees. J Hortic Sci Biotech 78:749-754

Lopez-Bernal A, Villalobos FJ, Garcia-Tejera O, Testi L, Orgaz F (2017) Do olive vegetative buds undergo a real dormant state in winter? Acta Hortic 1060:227-230

Mohammadi A, Mahmoudi MJ, Rezaee R (2013) Vegetative and reproductive responses of some apple cultivars (Malus domestica Borkh.) to heading back pruning. Int J AgriSci 3:628-635

Normand F, Bello AKP, Trottier C, Lauri P (2009) Is axis position within tree architecture a determinant of axis morphology, branching, flowering and fruiting? An essay in mango. Ann Bot 103:1325-1336

Rousseaux MC, Figuerola PI, Correa-Tedesco G, Searles PS (2009) Seasonal variations in sap flow and soil evaporation in an olive (Olea europaea L.) grove under two irrigation regimes in an arid region of Argentina. Agric Water Manag 96:1037-1044

Sanz-Cortés F, Martínez-Calvo J, Badenes ML, Bleiholder H, Hack H, Llácer G, Meier U (2002) Phenological growth stages of olive trees (Olea europaea). Ann Appl Biol 140:151-157 
Stanley J (2016) Factors affecting fruit set and fruit quality along branch units of different apricot cultivars. N Zeal J Crop Hortic 44:171-191

Stephan J, Lauri PE, Dones N, Haddad N, Talhouk S, Sinoquet H (2007) Architecture of the pruned tree: impact of contrasted pruning procedures over 2 years on shoot demography and spatial distribution of leaf area in apple (Malus domestica). Ann Bot 99:1055-1065

Tiyayon C, Strik B (2010) Effect of fruiting cane origin on fruitfulness of hardy kiwifruit, Actinidia arguta. New Zeal J Crop Hortic 31:179-186

Tombesi S, Molfese M, Cipolletti M, Visco T, Farinelli D (2014) Pruning technique in young high density hedgerow olive orchards. Acta Hortic 1057:385-390
Trentacoste ER, Puertas CM, Sadras VO (2010) Effect of fruit load on oil yield components and dynamics of fruit growth and oil accumulation in olive (Olea europaea L.). Eur J Agron 32:249-254

Vázquez-Valdivia V, Pérez-Barraza MH, Osuna-García JA, UríasLópez MA (2009) Intensidad de poda sobre el vigor, producción y peso del fruto, del mango 'Ataulfo'. Revista Chapingo Serie Horticultura 15:127-132

Vivaldi GA, Strippoli G, Pascuzzi S, Stellacci AM, Camposeo S (2015) Olive genotypes cultivated in an adult high-density orchard respond differently to canopy restraining by mechanical and manual pruning. Sci Hortic 192:391-399 